\title{
Career Aspiration And Perspective Among Students Pursuing Master Course In A Private Dental College, Chennai.
}

\author{
Karunya Ravi ${ }^{1}$, Pradeep Kumar ${ }^{2}$ \\ I (CRRI, Department of Public health dentistry, Saveetha dental college and hospital, India) \\ ${ }_{2}^{2}$ (Reader, Department of Public health dentistry, Saveetha dental college and hospital, India)
}

\begin{abstract}
The main objectives of this study is to assess the reason, interest, future aspiration and perspective among students pursuing masters in a dental college, Chennai. The present study was done on students pursuing Masters Degree (MDS) in dentistry in Saveetha Dental College, India, Chennai. The study population consists of 117 post graduate students, selected using convenience sampling. Students who are interested were included in the study. Structured questionnaire comprising of 10 questions was formulated in English, which was filled by the respondents. Data entry and data analysis was carried out. The response rate was $97.50 \% .76 .06 \%$ agreed doing post graduation is mandatory. In our study, $58.11 \%$ of students chose MDS due to their prior interest in the subject while only 6.83\% chose for job security. Oral surgery (29.81\%) has been subject of interest for many before counselling followed by orthodontics (19.60\%). 37.10\% of the post graduates considered joining a private dental college after their program. The study concludes that own interest and potential income are the major reasons for students pursuing master degree.
\end{abstract}

Keywords: career aspiration, dental post graduates

\section{Introduction:}

Dentistry has its unique hierarchy in society as professional health care worker but it is still an emerging field in India.

Increasing awareness about dental education among Indian population has raised their expectation from the dental practitioners and many patients prefer consulting a specialist, than a under graduate [1].

Increasing trend towards post graduation was observed with seniority among undergraduates [2]. As only limited seats are available for post graduation in dentistry, the students have to undergo heavy competition for pursuing their masters. Factors such as social standing and high professional status seem to be inspiring students to choose their major speciality. Many young graduates try to search other alternatives for career growth. Some look for overseas, health care management, clinical research and administration services, while some others quit health care and prefer different field [1].

Various studies have been conducted across the world to study motives for choosing dentistry as career option. These studies include studies conducted at India [2, 3, 4], Ireland [5], Iran [6], Brazil [7], United Kingdom [8], Nigeria [9], Peru [10] etc. There are very few studies that investigate the career aspiration and prospective among post graduate dental students [11,12].

Hence this study was planned to assess the reason, interest, future aspiration and perspective among students pursuing masters in a dental college, Chennai.

\section{Materials And Methodology:}

The present study was done on students pursuing master degree (M.D.S) in saveetha dental college and hospital. The college has been serving for more than 25 years in dentistry. Students from various states and countries undergo training in dentistry. Around 150 postgraduates undergo master degree program in this university. Students who voluntarily participated were included in the study. Before conducting the main survey a pilot study was done where the questionnaire was ascertained. The study population consisted of 117 students selected by Convenience sampling method. The Study was conducted after obtaining the ethical clearance from ethical committee of Saveetha University, Chennai. The time period set for collection of data from the students participating in this study is for a period of 2 weeks. A structured questionnaire comprising of 10 questions was formulated in English. The questionnaire was filled by respondents themselves and was supervised by an investigator. Data entry and data analysis was carried out and only completed filled questionnaire were taken for analysis.

\section{Results:}

The study population consisted of 117 students, 61 males and 56 females. Fig. 1 illustrates that $76 \%$ of study participants considered doing post graduation is mandatory. 
In response for their reasons to undergo post graduation, $58.11 \%$ joined on their own interest, followed by $17.09 \%$ preferred academic excellence, $15.6 \%$ as a source of potential income and $6.83 \%$ felt post graduation would provide them a secured job (Fig. 2)

Fig. 3 illustrates area of interest of study participants prior to counselling. Majority of students were interested in oral surgery $(29.81 \%)$ followed by orthodontics(19.60\%), Endodontics , Prosthdontics (12.08\%), Periodontics and Pedodontics (6.80\%), Oral medicine (5.12\%), Public health dentistry(4.27\%) and Oral pathology $(3.41 \%)$.

Fig. 4 depicts expectation of post graduates after pursuing master degree. $37.10 \%$ considered joining a academic institution as their front line choice, $30.06 \%$ of them fore see private practice to be a better source of income, $10.05 \%$ of them wanted to pursue their higher studies in abroad, $9.89 \%$ aspire to join a research institute, $6.83 \%$ preferred other field even after their post graduation.

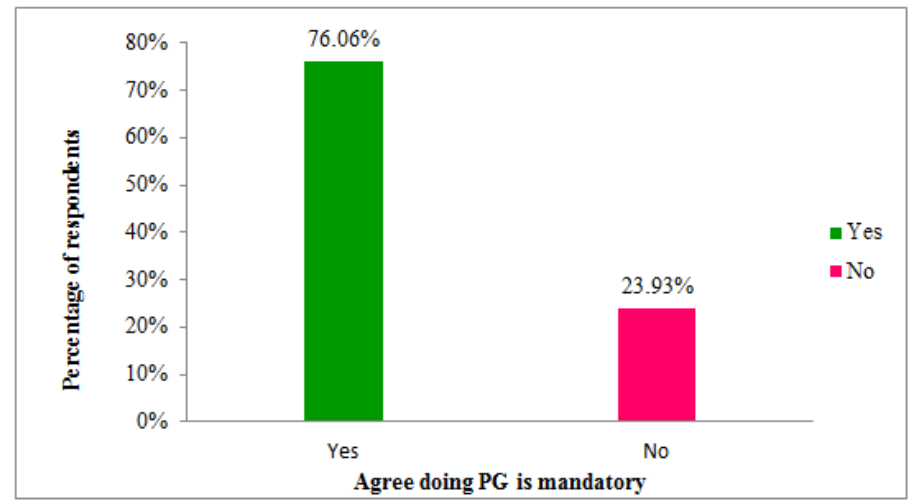

Fig. 1. View about pursuing Post graduation

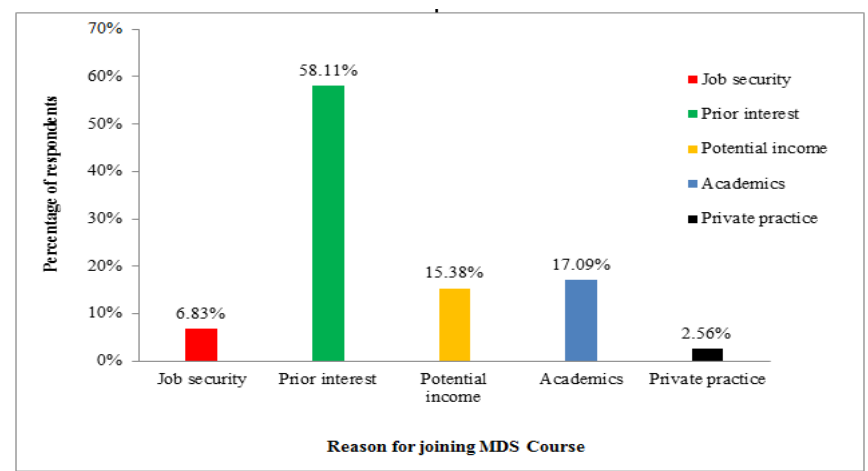

Fig. 2. Reasons for joining Post graduation program

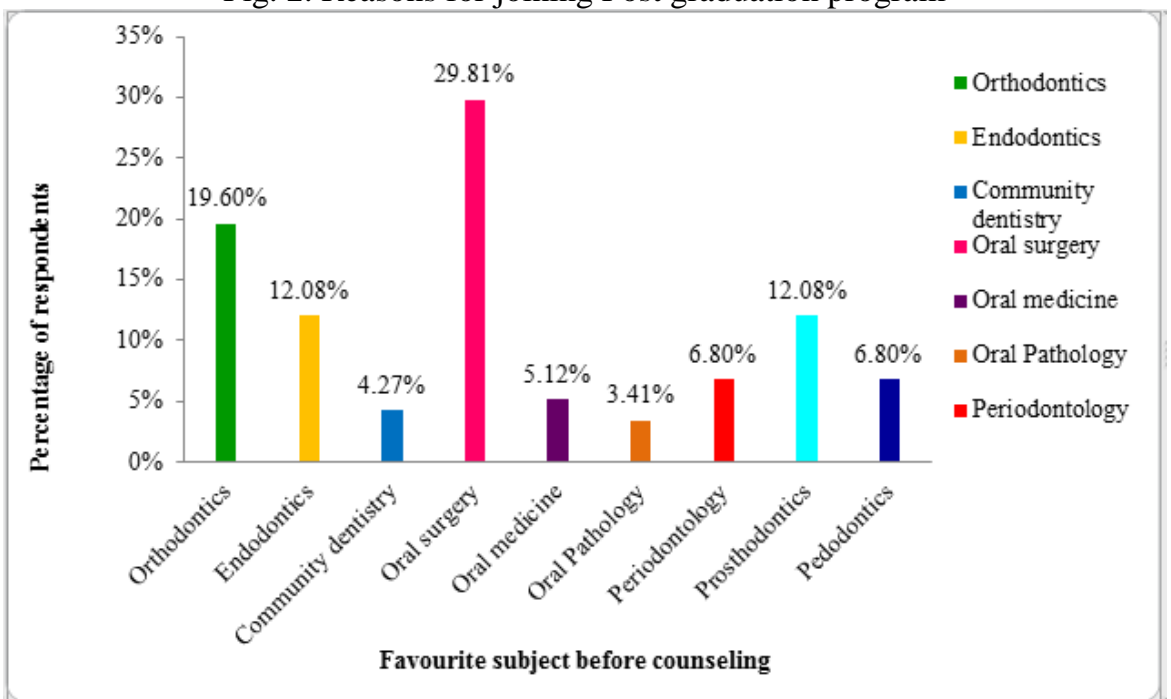

Fig. 3. Branch of interest before counselling 


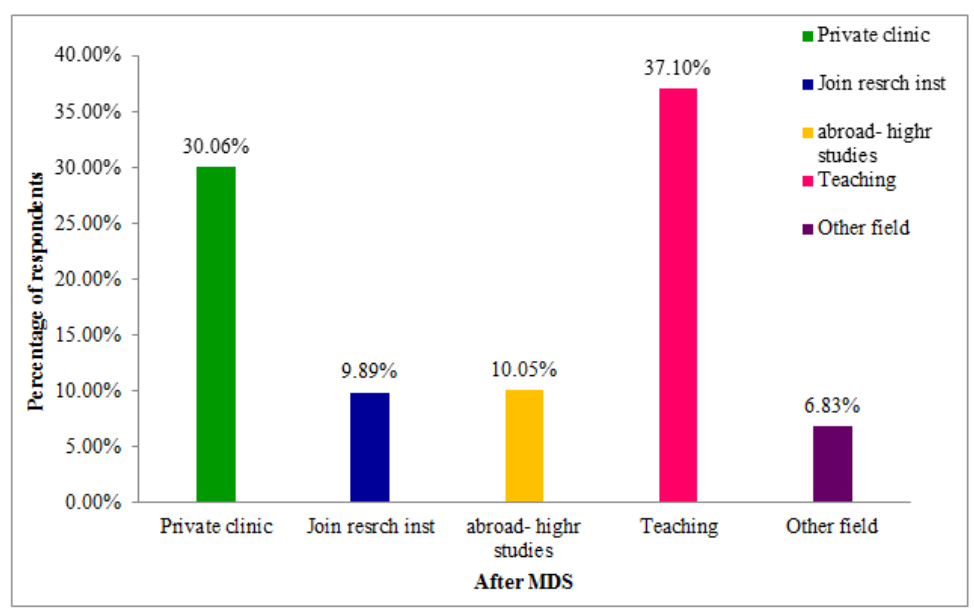

Fig. 4. Expectation of post graduates after pursuing master degree.

\section{Discussion:}

The response rate was $97.50 \%$. Most of study population considered doing post graduation to be mandatory. In our study, $58.11 \%$ chose post graduation due to their prior interest in the subject while only $6.83 \%$ chose for job security; where as in study conducted by Gurmukh singh in 2011, $27.1 \%$ chose master degree for job security [12].

In present study Oral surgery $(29.81 \%)$ has been subject of interest for many before counselling followed by orthodontics(19.60\%), similar findings was seen in studies conducted by Deepti Agarwal in 2008 and B.K. Garla in $2011[2,4]$.

In the present study $37.10 \%$ preferred affiliating to an academic institution and $30.06 \%$ considered to establish a private clinic after their master degree, while $6.83 \%$ of students preferred other field than dentistry even after their post graduation which shows career guidance should be tailored for students during and after their master degree to shape their future.

\section{Conclusion:}

The study has investigated and articulated the reasons for students pursuing post graduation which was mostly due to their self interest and potential income. It has also assessed the future aspirations and career perspective among students pursuing post graduation in Saveetha dental college and found most of the students were satisfied with their subject of choice and preferred joining academics and running private clinic after their course. This study has brought out the changing trends of doing post graduation. Finally, to consider the limitations of this study is that it is carried out under convenient sampling method and hence, similar type of studies might be conducted in other colleges to open up new vistas.

\section{Reference:}

[1] Hemanth jain and Aparna agarwal, Current scenario and crisis facing dental college graduates in India, Journal of Clinical and Diagnostic Research, 6 (1), 2012, 1-4.

[2] Deepti Agarwal, Vinayak Konkeri, Sunitha S and Reddy CVK, Reasons for choosing dentistry as a career aspiration of dental students in J.S.S Dental College and hospital, Mysore city, Journal of Indian Association of Public Health Dentistry, 11, 2008, 37-40.

[3] Chattopadhayay A and Chatterjee M, Career aspirations of dental students in a dental college in Calcutta, India. Indian Journal of Dental Research, 2, 1991, 10-12.

[4] Garla BK, Career aspirations and reason for choosing dentistry as career- A survey of dental students in Gandhi dental college and hospital, Bhubaneswar, Annals and essences of dentistry, 3(2), 2011, 108-110.

[5] Curtin S, Ray NJ, McKenna G and Burke FM, Supporting career choices in dentistry, Journal of Irish Dental Association, 58(1), 2012 , 43-44.

[6] Marzieh vahid Dastjerdi et al, Study motives and career choices of medical and dental students, Acta Medica Iranica, 50(6), 2012, 417-24.

[7] Mario do Carmo matias Frerir et al, Motivation towards career choice of brazilian Freshman students in a fifteen-year period, Journal of Dental Education, 75 (1), 2011, 115-121.

[8] Davies L, Thomas DR, Sandham SJ, Treasure ET and Chestnutt IG, Factors influencing the career aspirations and preferred modes of working in recent dental graduates Wales, Primary Dental Care, 15 (4), 2008, 157-163.

[9] Orenuga OO and daCosta OO, A survey of challenges and career aspirations of clinical dental students in Nigerian universities, Nigerian Dental Journal, 17, 2009, 19-23.

[10] Bernate E, Ieaza JL and EK Delgado-Anglo, Reasons for choosing dentistry as career- a study involving male and female first year students in Peru, European Journal of Dental Education, 10(4), 2006, 236-241.

[11] Dr.Pramila, Attitude among dental students concerning dental public health as a professional career, Journal of Indian Association of Public Health Dentistry, 14, 2009, 135-138.

[12] Gurmukh singh, Hiremath SS and Amandeep Kaur, Community dentistry as a career perspective among the students pursuing Masters course, Archives of Oral Science and Research, 1(3), 2011, 146-151.

[13] Stewart FMJ, Drummond JR, Carson L and Hoad Reddick G, The future of the profession - a survey of dental school applicants, British Dental Journal, 197, 2004, 569-573. 